\title{
TO THE ISSUE OF THE ESTIMATION OF RADON CONCENTRATIONS FOR RADON PROTECTION MEASURES
}

\author{
Aksionov N., Pavlenko T., Fryziuk M., German O., Fedorenko O., Mykhailenko O. \\ ДО ПИТАННЯ ОЦПККИ РІВНВВ РАДОНУ ДЛЯ ЗДІЙСНЕННЯ \\ ПРОТИРАДОНОВИХ ЗАХОДІВ
}

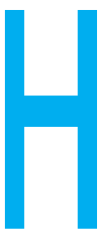

1 АКСЬОНОВ М.В. 1 ПАВЛЕНКО Т.О. 1 ФРИЗЮК М.А., 2 ГЕРМАН О., 1 ФЕДОРЕНКО О.В. 1 МИХАЙЛЕНКО О.В. 1 ДУ "Інститут громадського здоров'я ім. О.М. Марзєєва НАМН України", м. Київ, Україна

2 Шведська Агенція з радіаційного захисту (SSM), м. Стокгольм, Швеція

УДК $614.876: 613.5(1-22)$ : 546.296

Ключові слова: радон у повітрі приміщень, ґрунтове повітря, природні радіонукліди. ині у світі велика увага приділяється питанням забезпечення захисту населення від природного газу - радону, який є домінуючим джерелом у формуванні сумарної дози опромінення населення: його внесок може сягати понад 60\%. При цьому радон є другим за значущістю (після куріння) фактором ризику виникнення раку легенів $[1,2]$

За останні 10 років у світі було проведено понад 20 епідеміологічних досліджень впливу радону на здоров'я населення, виконаних методом «випадок контроль». Це дозволило провести пряму оцінку ризику для населення від опромінення радоном у будівлях без необхідності екстраполяції параметрів ризику, отриманих у дослідженнях серед шахтарів уранових шахт. За результатами цих досліджень встановлено, що 314\% випадків раку легенів обумовлено опроміненням населення радоном у житлі [3-6].
Обмеження опромінення населення радоном є важливою науково-практичною задачею, рішення якої нині набуває актуального значення у контексті громадського здоров'я.

Для виявлення радононебезпечних зон застосовується картування радонового ризику (як основний параметр використовується еквівалентна рівноважна об'ємна активність (ЕРОА) радону у повітрі будівель) або радонового потенціалу (як основний параметр використовується об'ємна активність (ОА) радону у ґрунтовому повітрі) [7].

Метою картування радонових ризиків $€$ виявлення територій, на яких розташовані будівлі з високими активностями радону у приміщеннях. Метою картування радонового потенціалу $€$ виявлення радононебезпечних територій: географічних ареалів або адміністратвних регіонів, виділених на підставі дослідження рівнів радону у повітрі ґрунтів [8].
К ВОПРОСУ ОЦЕНКИ УРОВНЕЙ РАДОНА ДЛЯ ПРОВЕДЕНИЯ ПРОТИВОРАДОНОВЫХ МЕРОПРИЯТИЙ

${ }^{1}$ Аксенов Н.В., 1 Павленко Т.А., 1 Фризюк М.А., 2Герман О., 1 Федоренко Е.В., 1 Михайленко А.В.

1 ГУ "Институт общественного здоровья им. А.Н. Марзеева НАМН Украины", г. Киев, Украина 2 Шведское Агентство по радиационной защите (SSM), г. Стокгольм, Швеция

Цель работы: оценка уровней радона в воздухе жилых зданий, в грунтовом воздухе, а также оценка содержания естественных радионуклидов (EPH) в почве для выбора противорадоновых мероприятий.

Материалы и методы исследования. Исследования включали измерения эквивалентной равновесной объемной активности (ЭРОА) радона-222 в воздухе жилых домов, а также объемной активности (OA) радона-222 в грунтовом воздухе и удельной активности естественных радионуклидов (ЕPH) в грунтах возле выбранных домов. Измерения ЭРОА радона-222 в воздухе помещений проводились методом пассивной трековой радонометрии с использованием в качестве детектора нитрат-целлюлозной пленки LR-115. Подсчет треков осуществлялся с помощью искрового счетчика. Измерения ОА радона-222 в грунтовом воздухе проводились экспрессным методом с помощью портативного радон-монитора AlphaGUARD в полевых условиях. Для определения удельной активности EPH (226Ra, 232Th и 40K) в почве применялся метод гамма-спектрометрии.

Результаты. Исследования проводились в селе Бакумовка Рокитнянского района Киевской области. Установлено, что уровни радона-222 в воздухе жилых домов превышают гигиенический норматив 100 Бк $\mathrm{M}^{-3}$ в $71 \%$ случаев. Диапазон значений ЭРОА радона-222 составлял 14521 Бк $M^{-3}$, среднее арифметическое значение - 159 Бк $M^{-3}$, среднее геометрическое 134 Бк м $^{-3}$ при стандартном отклонении 93 БК $M^{-3}$. Величины ОА радона в грунтовом воздухе составили 13-32 кБк $\mathrm{M}^{-3}$. Удельная активность ${ }^{226} R$ а составила 10-34 Бк кг $^{-1}$ на поверхности грунта и 22-37 Бк·кг-1 - на глубине. Таким образом, грунт, на котором расположены жилые дома, относится к грунтам с низким радоновым потенциалом ( $<50$ кБк $\left.\cdot M^{-3}\right)$ и низким содержанием ${ }^{226} \mathrm{Ra}\left(<50\right.$ Бк $\left.\cdot к \Gamma^{-1}\right)$.

Следовательно, высокие уровни радона-222 в жилых домах обусловлены их конструктивными особенностями. Для уменьшения облучения населения этого региона можно рекомендовать противорадоновые меры, направленные на корректировку конструктивных характеристик зданий.

Ключевые слова: радон в воздухе помещений, грунтовой воздух, естественные радионуклиды.

(ㄱ Аксьонов М.В., Павленко Т.О., Фризюк М.А., Герман О., Федоренко О.В., Михайленко О.В. СТАТТЯ, 2017. 
TO THE ISSUE OF THE ESTIMATION OF RADON CONCENTRATIONS FOR RADON PROTECTION MEASURES

${ }^{1}$ Aksionov N., 1 Pavlenko T., 1 Fryziuk M., 2 German O., 1 Fedorenko O., 1 Mykhailenko 0. 1 SI "O.M. Marzeiev Institute for Public Health NAMSU", Kyiv, Ukraine

2 The Swedish Agency for Radiation Protection, Stockholm, Sweden

Objective. We assessed the indoor radon concentrations of residential buildings, radon concentrations in soil air, and natural radionuclides' (NORM) concentration in soil for the selection of radon protection measures.

Materials and methods. The measurements of the indoor equivalent equilibratory concentration of ${ }^{222} R n(E E R C)$ in indoor air of residential buildings, ${ }^{222} \mathrm{Rn}$ concentration in soil air, and the concentration of natural radionuclides (NR) in soil near the selected buildings were included in the studies. Measurements of indoor radon-222 EERC were carried out with the help of passive track radonometry method with nitrate-cellulose film LR-115 as a detector. Calculation of the tracks was carried out with the help of spark counter. Measurements of radon-222 concentrations in soil air were carried out by the express method with the help of portable radon monitor Alpha GUARD under field conditions. To determine the NORM (226Ra, ${ }^{232} \mathrm{Th}$ and $\left.{ }^{40} \mathrm{~K}\right)$ concentration in soil, we applied the gamma-spectrometry method.

Results. The studies were performed in the village of Bakumovka, Rokytne region, Kyiv region.

The EERCs in the indoor air of residential buildings were established to be exceeded the hygienic standards of $100 \mathrm{~Bq} \cdot \mathrm{m}^{-3}$ in $71 \%$ of cases. The range of indoor EERC made $14-521 \mathrm{~Bq} \cdot \mathrm{m}^{-3}$, the arithmetic mean was $159 \mathrm{~Bq} \cdot \mathrm{m}^{3}$, the geometric mean was $134 \mathrm{~Bq} \cdot \mathrm{m}^{-3}$ at a standard deviation of $93 \mathrm{~Bq} \cdot \mathrm{m}^{-3}$. Radon concentration values in soil air were 13$32 \mathrm{kBq} \cdot \mathrm{m}^{-3},{ }^{-226} \mathrm{Ra}$ concentrations accounted for 10-34 Bq $\cdot \mathrm{kg}^{-1}$ at soil surface and 22-37 Bq $\cdot \mathrm{kg}^{-1}$ at depth. Thus, the soil at the location of the buildings belongs to the area with a low radon risk

$\left(<50 \mathrm{kBq} \cdot \mathrm{m}^{-3}\right)$ and low concentration of ${ }^{226} \mathrm{Ra}$ $\left(<50 \mathrm{~Bq} \cdot \mathrm{kg}^{-1}\right)$. So, the high levels of ${ }^{222} \mathrm{Rn}$ in residential buildings are due to their design features. For the reduction of the population's exposure in this region, the radon protection measures, directed on the correction of buildings' design features, may be recommended.

Keywords: indoor radon, soil air, NORM.
Основним підходом до картування радонового ризику є графічне відображення комбінованих геологічних даних щодо території та результатів вимірювання радону у повітрі будинків або повітрі ґрунтів [9].

Метою роботи $\epsilon$ оцінка рівнів радону у повітрі житлових будівель, ґрунтовому повітрі, а також вмісту природних радіонуклідів (ПРН) у ґрунті для вибору протирадонових заходів.

Огляд проблеми. Радон-222 - це газ, який утворюється при радіоактивному розпаді природних радіонуклідів уранового ряду. Під час розпаду він утворює короткоіснуючі дочірні продукти розпаду (ДПР) - полоній, свинець, вісмут, які, приєднуючись до часток пилу чи вологи, утворюють радіоактивний аерозоль. Потрапляючи у легені, радіоактивний аерозоль опромінює бронхіальний епітелій. Це призводить до відносно високих доз опромінення, які спричиняють додатковий ризик захворювання на рак легенів.

Результати аналізу об'єднаних епідеміологічних досліджень у житлі, проведеного останніми роками у рамках радонового проекту ВООЗ, переконливо продемонстрували, що ризик раку легенів збільшується лінійно $з$ довгостроковою радоновою експозицією (30 років), при цьому немає свідчень наявності порогу, а ризик зростає статистично значуще навіть за помірних вмістів радо- ну у житлових приміщеннях (50100 БK $\left.\cdot \mathrm{M}^{-3}\right)[2-5,10]$.

За результатами цих досліджень 2015 року Міжнародна комісія з радіологічного захисту (МКР3) видала нові рекомендації (Публікація 126 [10]), в яких ризик від радону для бронхолегеневої системи людини майже вдвічі вищий за колишне значення, рекомендоване у публікації 65 МКР3 (1994) [11].

Згідно з новими європейськими стандартами безпеки [8] кожна країна повинна мати Національний план дій щодо радону, який має включати, зокрема, оцінку та картування радонових ризиків для проведення протирадонових заходів.

У концепції радонового ризику важливе значення має картування регіону. Першим кроком у створенні карт радонового ризику є збір усієї доступної інформації про геологічні та гідрологічні характеристики ґрунтів, їхні типи тощо. Далі проводяться вимірювання ЕРОА радону у повітрі будинків і ОА радону у воді. Ця інформація служить основою для планування польових досліджень 3 картування радону.

Наступним кроком $€$ проведення гамма-спектрометричних вимірювань вмісту ПРН у ґрунті та OA радону у ґрунтовому повітрі 3 зазначенням координат точок вимірювання за системою позиціонування GPS.

Картування рівнів радону у ґрунті застосовується 3 метою прогнозування його вмісту у повітрі будівель, які планується збудувати на конкретній ділянці, або для вибору тих чи інших протирадонових заходів для будинків, які вже експлуатуються.

Отримані дані обробляються комплексно. За результатами аналізу досліджувану територію відносять до однієї з трьох основних градацій зон ризику: високого, нормального або низького, що відображається на топографічній карті [12].

Разом з виявленням радононебезпечних зон необхідно досліджувати особливості інженерно-планувальних рішень будівель, які можуть обумовлювати високі рівні радону у повітрі приміщень навіть при розташуванні цих будівель у зонах низького радонового потенціалу [10].

Матеріали та методи дослідження. Дослідженнями передбачені вимірювання ЕРОА радону-222 у повітрі житлових приміщень методом пасивної трекової радонометрії, експресне вимірювання ОА радону-222 у ґрунтовому повітрі, гамма-спектрометричні вимірювання природних радіонуклідів (ПРН) (226Ra, 226Th та 40K) у ґрунтах.

Вимірювання ЕРОА радону-222 у повітрі приміщень проводилися відповідно до вимог "Норм радіаційної безпеки України (НРБУ97)". Методику вимірювань EPOA радону-222 у повітрі приміщень затверджено головним державним санітарним лікарем 
України Постановою № 63 від 08.08.2000 року. Застосовувався метод пасивної трекової радонометрії з використанням в якості детектора нітрат-целюлозної плівки LR-115 (Kodak).

Вимірювання проводилися в опалювальний період. Час експонування радонових накопичувачів становив не менше 30 діб.

При встановленні радонових накопичувачів у будинку на кожен прилад заповнювався сертифікат, до якого заносилися дані щодо дат експонування, характеристик будівлі тощо.

По завершенні експонування детектори зазнавали хімічної обробки, після якої визначали кількість треків (щільність) методом іскрового підрахунку за допомогою іскрового лічильника (АИСТ).

Вимірювання ОА радону-222 (222Rn) у ґрунтовому повітрі були здійснені експресним методом за допомогою портативного радон-монітора AlphaGUARD PQ2000 PRO RnTn у польових умовах, безпосередньо на місці обраних точок вимірювання.

Принцип методу полягає у тому, що ґрунтове повітря через фільтри від вологи та дочірніх продуктів розпаду (ДПР) радону нагнітається до іонізаційної камери радон-монітора за допомогою насоса шляхом активного прокачування через забитий у ґрунт на глибину 7080 см пробовідбірник.

Після прокачування 1 л ґрунтового повітря через іонізаційну камеру (детектор) починається процес вимірювання. Радон та його ДПР, що потрапили до камери, при розпаді випромінюють альфа-частинки, які створюють іонізаційний струм всередині камери. Імпульси напруги іонізаційного струму реєструються, посилюються і вимірюються: розраховується їхня площа та розподіляється за енергіями каналами аналізатора. На основі отриманих спектрів розраховується ОА радону, яка усереднюється за час циклу вимірювання. Величина ОА радону відображається на дисплеї. Усі отримані дані фіксуються у пам'яті радон-монітора.

Для вимірювання питомої активності ПРН (226 Ra, 232Th, 40K) у ґрунті застосовувався метод гамма-спектрометрії з використанням портативного дозиметра (гамма-спектрометра) identiFINDER2-NGH (FLIR, CШA).

Метод ґрунтується на залежності інтенсивності гаммавипромінювання від питомої активності радіоактивного еле- мента у зразку. У результаті взаємодії гамма-квантів з речовиною на виході детектора виникають електричні заряди, величина яких пропорційна енергії, втраченій гамма-квантом у детекторі. Амплітудний розподіл сигналів відповідає спектру випромінювань.

Гамма-спектрометричне вимірювання зразків відбувається у три етапи: одержання амплітудного розподілу випромінювання зразка за енергією (запис спектра); виявлення статистично значущих піків у спектрі та якісна ідентифікація радіонуклідів за цими піками; розрахунок активності радіонуклідів.

Для визначення питомої активності ПРН гамма-спектрометр встановлювався на поверхню ґрунту на час вимірювання 300 500 с. Наступне вимірювання здійснювалося на глибині 7080 см у ґрунті в ямі. Це дозволило зробити поправку на внесені з добривами ПРН, порівнявши їх 3 відповідними значеннями на поверхні ґрунту. Отримані результати вимірювань питомої активності ПРН на глибині 70-80 см перераховувалися 3 поправкою на $2 \pi$ геометрію з урахуванням калібрувальних факторів.

Математична обробка передбачала розрахунок первинних статистичних показників (дескриптивна статистика). Основна частина математичної обробки виконувалася з застосуванням стандартного статистичного пакета "STATISTICA 10.0".

Результати та обговорення Дослідження проводилися у

\section{Частотний розподіл ЕРОА радону-222 у повітрі будинків с. Бакумівка Рокитнянського району Київської області \\ Рисунок 1}

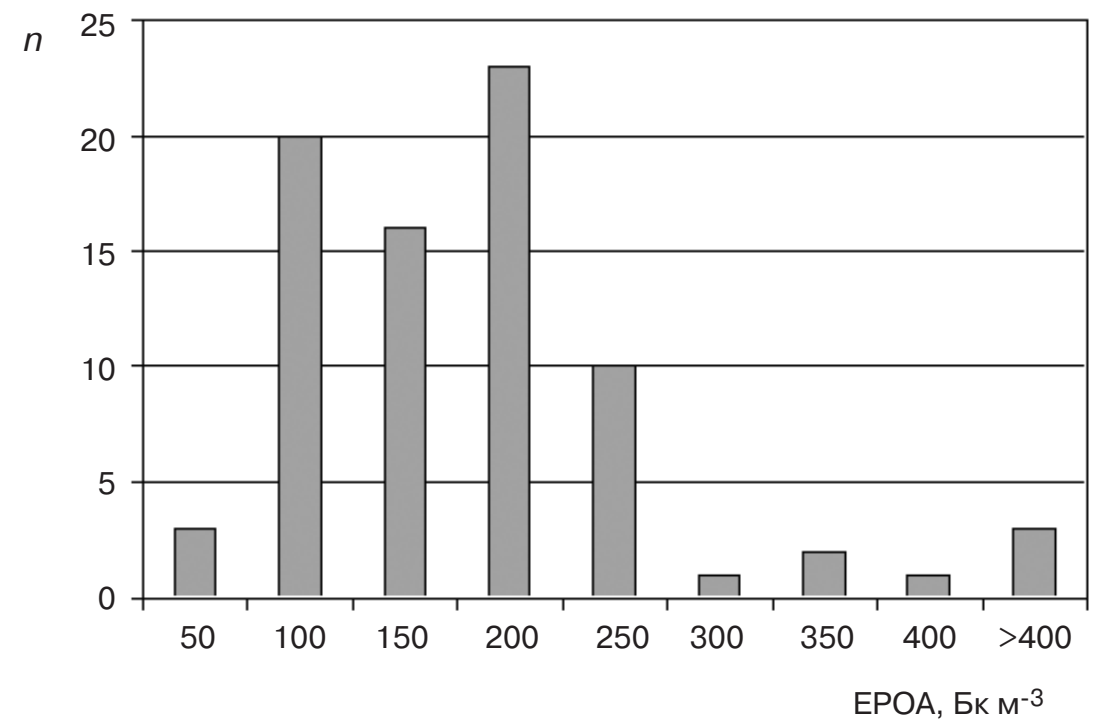

Примітка: $n-$ кількість будинків.

селі Бакумівка Рокитнянського району Київської області.

На першому етапі роботи були проведені вимірювання ЕРОА радону-222 у повітрі будинків (79 вимірювань).

ЕРОА радону-222 у повітрі приміщень житлових будинків у вигляді частотного розподілу по всьому масиву даних представлено на рисунку 1 .

Діапазон значень ЕРОА радону-222 становив від 14 Бк $\cdot \mathrm{M}^{-3}$ до 521 Бк $\cdot \mathrm{M}^{-3}$, середнє арифметичне значення ЕРОА склало $159 \mathrm{БK} \cdot \mathrm{M}^{-3}$, середнє геометричне - 134 Бк $\cdot \mathrm{M}^{-3}$ за стандартного відхилення 93 Бк $\cdot \mathrm{M}^{-3}$.

Загалом у даному населеному пункті зафіксовано перевищення гігієнічного нормативу для житлових будинків (100 Бк $\left.\cdot \mathrm{M}^{-3}\right)$ у $71 \%$ випадків. Крім того, встановлено, що у будівлях зустрічається перевищення рівня 200 Бк $\cdot \mathrm{M}^{-3}$ у $22 \%$ випадків та рівня понад 400 Бк $\mathrm{M}^{-3}-\mathrm{y}$ 5\% випадків.

На другому етапі дослідження за даними аналізу результатів вимірювань було обрано дві будівлі (об'єкти № 1 та № 2), в яких рівні EPOA радону-222 перевищують гігієнічний норматив у 2 рази (223 Бк $\cdot \mathrm{M}^{-3}$ та 200 Бк $\cdot \mathrm{M}^{-3}$ відповідно). Поблизу цих об'єктів в обраних точках проведено вимірювання ОА радону-222 у ґрунтовому повітрі та вмісту ПРН у ґрунті для визначення радононебезпечності прилеглої території.

Паралельно вимірюванням, за згодою власників будинків, було проведено аналіз інженернопланувальних рішень будинків

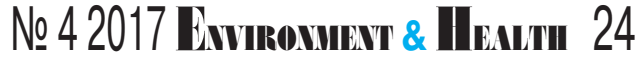


які $€$ типовими для існуючої забудови Київщини.

Основні характеристики об'єктів дослідження. Об'єкт № 1 являє собою 4-кімнатний будинок з кухнею, збудований у 60-ті роки минулого століття з дерева та обкладений червоною цеглою по усьому фасаду. Цеглу виготовлено з місцевих глин. Глибина підпільного простору різна в усіх частинах будинку - від 25 см до 75 см. Дерев'яна підлога не ізольована і має безліч щілин. Підпільний простір не вентилюється. Вікна відкриваються лише у деяких кімнатах. Для опалення використовується газовий котел. У будівлі немає систем водопостачання та каналізації.

Об'єкт № 2 являє собою 5-кімнатний будинок, збудований у 70-ті роки минулого століття 3 червоної цегли, виготовленої з місцевих глин. Фундамент збудований з гранітних каменів із місцевого кар'єру і має глибину близько 100 см. У фундаменті відсутні вентиляційні отвори, тобто немає провітрювання підпільного простору. Будинок опалюється газом. Хоча є стара пічка, але нею більше не користуються, і димар закритий. Дерев'яна підлога не ізольована і має щілини між дошками. Вікна наглухо зачинені навіть у літню пору і ніколи не відкриваються. У будівлі немає систем водопостачання та каналізації.

На об'єкті № 1 середнє значення ОА радону-222 у ґрунтовому повітрі склало $22 \mathrm{KБ \kappa} \cdot \mathrm{M}^{-3}$ (діапазон значень 13-32 кБк $\cdot \mathrm{M}^{-3}$ ) за стандартного відхилення 7 кБк $\cdot \mathrm{M}^{-3}$, на об'єкті № 2 - 18 кБк $\cdot \mathrm{M}^{-3}$ (діапазон значень 13-20 кБк $\cdot \mathrm{M}^{-3}$ ) і 4 кБк $\cdot \mathrm{M}^{-3}$ відповідно.

Графічне відображення результатів дескриптивної статистики щодо рівнів вмісту радону222 у повітрі ґрунту на двох об'єктах надано на рисунку 2.

Вимірювання питомої активності ${ }^{226} \mathrm{Ra}$, ${ }^{232} \mathrm{Th}$ та $40 \mathrm{~K}$ здійснювались у тих точках, де проводилися дослідження ОА радону-222 у ґрунтовому повітрі на поверхні ґрунту і на глибині 70-80 см.

Встановлено, що значення питомої активності ${ }^{226} \mathrm{Ra}$ у ґрунті варіюють від 10 Бк•кГ-1 до 34 Бк $\mathrm{K}^{-1}$ (на поверхні) та від 22 Бк кг $^{-1}$ до 37 Бк $\cdot \mathrm{K}^{-1}$ (на глибині).

Загалом у с. Бакумівка у середньому питома активність ПРН у ґрунті (на поверхні та на глибині) становила відповідно за ${ }^{226} \mathrm{Ra}$ - 23 Бк $\cdot \mathrm{K}^{-1}$ i 29 Бк $\cdot \mathrm{K}^{-1}, 232 \mathrm{Th}-$ 36 БК $\cdot \mathrm{K}^{-1}$ i 41 БK $\cdot \mathrm{K}^{-1}$ та $40 \mathrm{~K}-550$ БК $\cdot \mathrm{K}^{-1}$ i 604 БК $\cdot \mathrm{K}^{-1}$

Виявилося, що розподіл ПРН у ґрунті практично однаковий і на поверхні, і на глибині. Відсотковий внесок за величиною вмісту кожного радіонукліда у ґрунті представлено на рисунку 3.

Як видно з рисунка 3, найбільша частка за питомою активністю серед усіх ПРН припадає на $40 \mathrm{~K}(90 \%)$.

Максимальне значення питомої активності $40 \mathrm{~K}$ у ґрунті становить 775 Бк $\mathrm{K}^{-1}$ (об'єкт № 2, точка на поверхні ґрунту). Максимальне значення активності ${ }^{226} \mathrm{Ra}$ у ґрунті, продуктом розпаду якого є радон-222, становить 37 Бк $\cdot \mathrm{K}^{-1}$ (об'єкт № 1, точка на глибині ґрунту).

Однак величини питомої активності ПРН у ґрунті на поверхні дещо менші, ніж на глибині: за ${ }^{226} \mathrm{Ra}$ - на 21\%, 232Th - 10\%, 40 K - 9\%. На рисунку 4 представлено для порівняння усереднений вміст ПРН у ґрунті на поверхні та на глибині.

Співвідношення між питомою активністю ПРН на поверхні та на глибині за ${ }^{226} \mathrm{Ra},{ }^{232} \mathrm{Th}$ та ${ }^{40 \mathrm{~K}}$ становлять 0,79, 0,90 та 0,91.

В Україні відсутня класифікація ґрунтів за радононебезпечністю. Однак за міжнародною

ляції підпільного простору, наявність щілин у підлозі, наглухо зачинені вікна (відсутність провітрювання кімнат) тощо.

Таким чином, для зменшення дозового навантаження від радону-222 населення дослідженого регіону можна рекомендувати проведення досить простих протирадонових заходів, а саме: герметизацію підлоги, монтаж віддушин у підпільному просторі або встановлення там примусової вентиляції, встановлення вікон з режимом провітрювання тощо

\section{Висновки}

1. У досліджених житлових будинках у с. Бакумівка Рокитнянського району Київської області зафіксовано перевищення гігієнічного нормативу 100 Бк $\cdot \mathrm{M}^{-3}$ щодо ЕРОА радону222 у повітрі приміщень у $71 \%$ випадків, у тому числі перевищення рівня 200 Бк $\cdot \mathrm{M}^{-3}-$ - $22 \%$ випадків та рівня понад 400 Бк $\mathrm{M}^{-3}$ - у 5\% випадків.

2. Ґрунт, на якому розташовані досліджені будівлі, має низький радоновий потенціал (ОА радону-222 у повітрі ґрунту <50 $\left.\mathrm{KБK} \cdot \mathrm{M}^{-3}\right)$. Значення питомої активності 226Ra становлять 10 -

Рисунок 2

Діапазон значень ОА радону-222 у ґрунтовому повітрі біля досліджених будинків

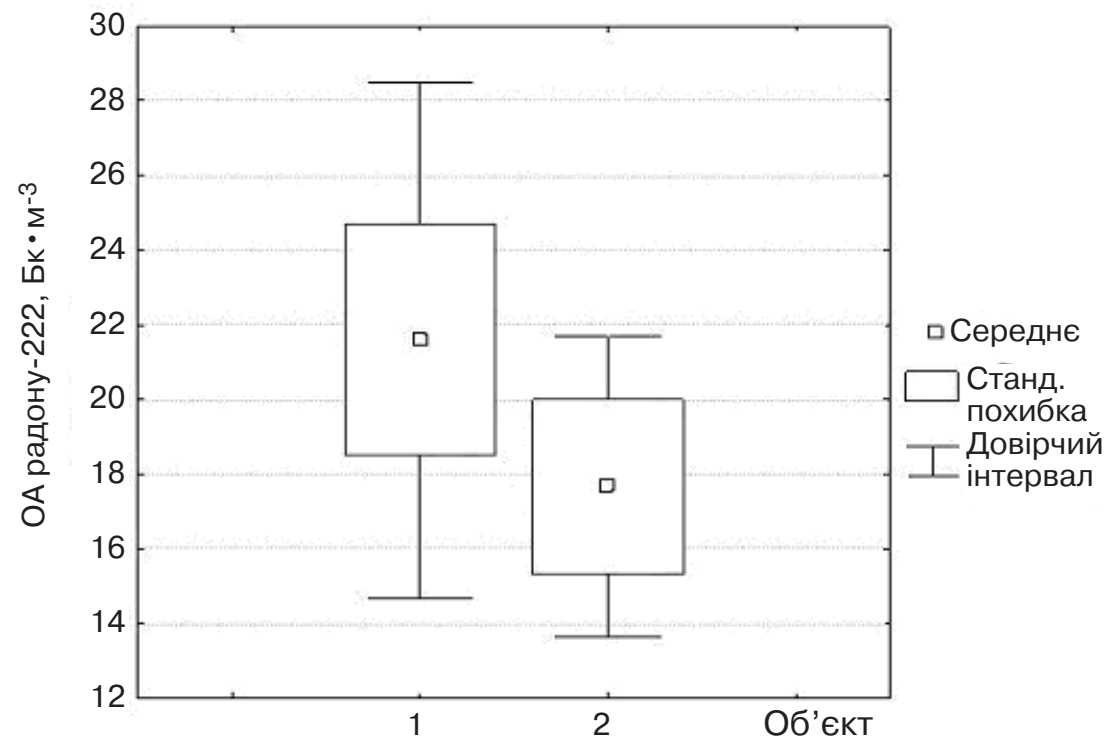

класифікацією досліджені ґрунти у с. Бакумівка можна віднести до ґрунтів з низьким вмістом радону у ґрунтовому повітрі $\left(<50\right.$ кБк $\left.\cdot \mathrm{M}^{-3}\right)$ та низьким вмістом ${ }^{226} \mathrm{Ra}\left(<50 \mathrm{KБК} \cdot \mathrm{M}^{-3}\right)$.

Водночас перевищення гігієнічного нормативу щодо ЕРОА радону-222 у повітрі приміщень свідчить, що на формування високих рівнів радону впливають конструктивні особливості будівель: відсутність венти-
Рисунок 3

Структура вмісту ПРН ${ }^{226}$ Ra, 232Th та 40K у ґрунті

Радій-226 Торій-232 $4 \% \quad 6 \%$

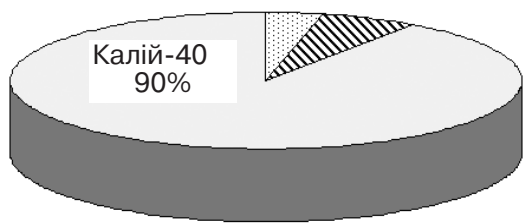


34 Бк $\kappa^{-1}$ на поверхні ґрунту та 22-37 Бк $\cdot к \Gamma^{-1}$ - на глибині.

3. Високі рівні радону-222 у повітрі досліджених будівель обумовлені конструктивними особливостями.

4. Для зменшення опромінення населення дослідженого регіону від радону можна рекомендувати протирадонові заходи, спрямовані на коректування конструктивних характеристик будівель.

ЛІТЕРАТУРА

1. United Scientific Committee on the Effects of Atomic Radiation. Exposure from Natural Radiation Sources. UNSCEAR 2000 Report : Annex B. New York : United Nations, 2000. 74 p.

2. United Scientific Committee on the Effects of Atomic Radiation . Source-to-effects Assessment for Radon in Homes and Workplaces. UNSCEAR 2006 Report : Annex E. New York : United Nations, 2009. 138 p.

3. Darby S., Hill D., Auvinen A. et al. Radon in Homes and Risk of Lung Cancer: Collaborative Analysis of Individual Data from 13 European Case-Control Studies. British Journal of Medicine, 2005. Vol. 330. 223 p.

4. Lubin J.H., Wang Z.Y., Boice J.D. et al. Risk of Lung Cancer and Residential Radon in China: Pooled Results of Two Studies. International Journal of Cancer, 2004. Vol. 109. 132-137.

5. Darby S., Hill D., Auvinen A. et al. Residential Radon and Lung Cancer - Detailed Results of a Collaborative Analysis of Individual Data on 7148 Persons with Lung Cancer and 14208 Persons without Lung Cancer from 13 Eidemiological Studies in Europe. Scand. J. Work Environ. Health, 2006. Vol. 32 (1). 1-84

6. Zeeb H., Shannoun F. (eds.).
WHO Handbook on Indoor Radon: a Public Health

Perspective. WHO, 2009. 94 p.

7. Clavensjo B., Akerblom G.

Radon Book. Measures against

Radon. Stockholm : Formas

(BFR), SSI. 1994. 131 p.

8. Council Directive

2013/59/EURATOM of 5 December

2013 Laying Down Basic Safety

Standards for Protection against

the Dangers Arising from Exposure

to lonising Radiation, and Repealing Directives 89/618/Euratom,

90/641/Euratom, 96/29/Euratom,

97/43/Euratomand 2003/122/

Euratom. Official Journal of the

European Union. 17.1.2014. $73 p$.

available at : http://eur-lex.europa. eu/lexuriserv/lexuriserv.do?uri=oj:I: 2014:013:0001:0073:en:pdf

9. Kemski J., Klingel R., Siehl A., Valdivia-Manchego M. From Radon Hazard to Risk Prediction - Based on Geological Maps, Soil Gas and Indoor Measurements in Germany. Environ. Geol. 2009.

Vol. 56. 1269-1279.

10. Radiological Protection against Radon Exposure. ICRP Publication 126. Annals of the ICRP. 2014. Vol. 43 (3). 73 p.

11. Protection Against Radon222 at Home and at Work. ICRP Publication 65. Annals of the ICRP. 1994. Vol. 23 (2). 78 p.

12. Sundйn G., Maxe L., Leng L.-O. Regional цvervakning av grundvattenkemi. Utvдrdering avdelprogram. SGU-rapport 2014:23.

Stockholm, 2014. 54 p.

REFERENCES

1. United Scientific Committee on the Effects of Atomic Radiation. Exposure from Natural Radiation Sources. UNSCEAR 2000 Report : Annex B. New York : United Nations; 2000 : 74 p.

2. United Scientific Committee

Рисунок 4

Питома активність ${ }^{226} \mathrm{Ra}$, ${ }^{232} \mathrm{Th}$ та $40 \mathrm{~K}$ у ґрунті с. Бакумівка Рокитнянського району Київської області

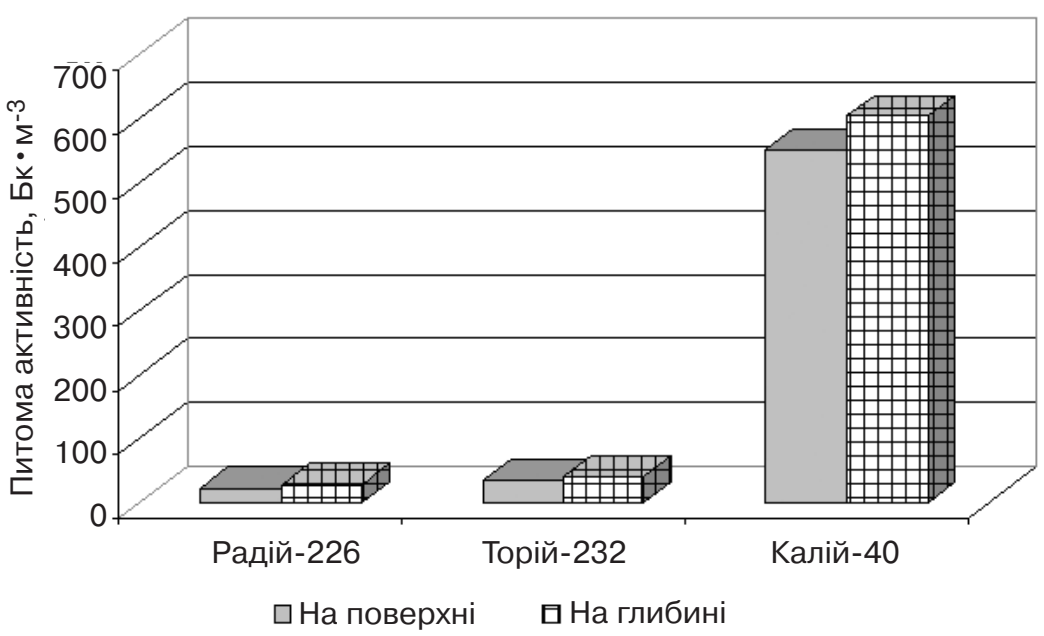

on the Effects of Atomic Radiation . Source-to-effects Assessment for Radon in Homes and Workplaces. UNSCEAR 2006 Report : Annex E. New York : United Nations ; 2009 : 138 p.

3. Darby S., Hill D., Auvinen A. et al. Radon in Homes and Risk of Lung Cancer: Collaborative Analysis of Individual Data from 13 European Case-Control Studies. British Journal of Medicine. 2005 ; $330: 223$ p.

4. Lubin J.H., Wang Z.Y., Boice J.D. et al. Risk of Lung Cancer and Residential Radon in China: Pooled Results of Two Studies. International Journal of Cancer. 2004 ; 109 : 132-137.

5. Darby S., Hill D., Auvinen A. et al. Residential Radon and Lung Cancer - Detailed Results of a Collaborative Analysis of Individual Data on 7148 Persons with Lung Cancer and 14208 Persons without Lung Cancer from 13 Eidemiological Studies in Europe. Scand. J. Work Environ. Health. 2006 ; 32 (1) : 1-84.

6. Zeeb H. and Shannoun F. (eds.). WHO Handbook on Indoor Radon: a Public Health Perspective. WHO ; 2009 : 94 p.

7. Clavensjo B. and Akerblom G. Radon Book. Measures against Radon. Stockholm : Formas (BFR), SSI; 1994 : $131 \mathrm{p}$

8. Council Directive 2013/59/ EURATOM of 5 December 2013 Laying Down Basic Safety Standards for Protection against the Dangers Arising from Exposure to lonising Radiation, and Repealing Directives 89/618/Euratom, 90/ 641/Euratom, 96/29/Euratom, 97/ 43/Euratomand 2003/122/ Euratom. Official Journal of the European Union. 17.1.2014: 73 p. available at : http://eur-lex.europa.eu/lexuriserv/lexuriserv. do?uri=oj:1:201 4:013:0001:0073:en:pdf.

9. Kemski J., Klingel R., Siehl A. and Valdivia-Manchego M. From Radon Hazard to Risk Prediction - Based on Geological Maps, Soil Gas and Indoor Measurements in Germany. Environ. Geol. 2009 ; 56 : 1269-1279.

10. Radiological Protection against Radon Exposure. ICRP Publication 126. Annals of the ICRP. 2014 ; 43 (3) ; 73 p.

11. Protection Against Radon222 at Home and at Work. ICRP Publication 65. Annals of the ICRP. 1994 ; 23 (2) : 78 p.

12. Sundйn G., Maxe L. and Leng L.-O. Regional цvervakning av grundvattenkemi. Utvдrdering avdelprogram. SGU-rapport 2014:23. Stockholm ; 2014 : 54 p. Надійшла до редакції 15.06.2017 